\title{
Severity of Coronary Artery Disease associated with Non-Alcoholic Fatty Liver
}

\section{Albair Abdulmaseh ${ }^{\mathrm{a}}$, Mohamed Elsenebsy ${ }^{\mathrm{a}}$, Hosam Ismael $^{\mathrm{a}}$, Mohammed Tag-Adeen ${ }^{\mathrm{a}}$ \\ ${ }^{a}$ Internal Medicine Department, Qena Faculty of Medicine,South Valley University.}

\begin{abstract}
Background: Non-Alcoholic Fatty Liver Disease (NAFLD) is closely related to several metabolic disorders and is also associated with increased risk of cardiovascular disease (CVD), including coronary artery disease (CAD).

Patients and methods: This was a prospective study involving patients who underwent coronary catheterization and had proven coronary artery diseases. All patients were subjected to abdominal ultrasonography and transient elastography to detect NAFLD and grading of steatosis . Results: A total of 100 patient, with mean ageof $47.9 \pm 8.4$ years, $70 \%$ were males , $70 \%$ were diabetics. According to ultrasonographic findings, there were 58 patients (58\%) normal and 42 patients (42\%) with fatty liver. As regard degree of steatosis, there were 12 patients (12\%) of S0, 38 patients (38\%) of S1, 22 patients (22\%) of S2 and 28 patients (28\%) of S3.The mean of Genseni score was 50.9.There was highly statistical significant correlation (p-value < 0.001) between degree of steatosis and Genseni score in studied patients, the mean of Gensini score was 10.5, 21.7, 57.6 and 102.6 in Grade S0, S1, S2 and S3 respectively. Conclusion: The present study indicated a Statistically significant correlation between CAD and NAFLD.
\end{abstract}

Key Words: Non-Alcoholic Fatty Liver Disease, Coronary Artery Disease, Gensini score.

\section{Introduction:}

Nonalcoholic fatty liver disease (NAFLD) is a common liver disease with an estimated prevalence of up to $30 \%$ in the general population (Chalasani et al., 2012).It encompasses a histologic spectrum ranging from simple steatosis to steatohepatitis and advanced fibrosis (Lee et al., 2017). Because NAFLD is related to metabolic syndrome and obesity, many patients with NAFLD have coronary artery disease (CAD). Several studies have reported that NAFLD is a strong independent risk factor for CAD (Targher et al., 2006). Several studies have reported that NAFLD is a strong independent risk factor for CAD (Kim et al., 2012). Coronary artery disease (CAD) is a cardiovascular disease which has been found to be the leading cause of death in both developed and developing countries (Naghavi et al., 2015). CAD is an atherosclerotic disease which is inflammatory in nature, manifested by stable angina, unstable angina, myocardial infarction or sudden cardiac death (Álvarez-Álvarez et al., 2017). 
In Egypt, mortality secondary to CAD is rapidly rising (Ibrahim et al., 2013).

According to the latest WHO data, coronary artery disease deaths in Egypt reached 78,879 or $21.73 \%$ of total deaths. The age adjusted death rate is 173.98 per 100000 of population ranks Egypt 33 in the world (Bahnasawyet al., 2013).

\section{Objectives:}

To evaluate correlation between severity of Coronary Artery Disease and Non-Alcoholic Fatty Liver Disease.

\section{Patients and methods:}

This was a prospective study involving 100 Egyptian patients and carried out at Internal medicine department, Qena Hospital University ,Faculty of Medicine, South Valley University.

Patients were selected according to the following:

\section{Inclusion criteria}

Patients who underwent coronary catheterization and had proven coronary artery diseases were enrolled.

\section{Exclusion criteria}

Patientswith other potential causes of chronic liver disease were excluded, including those with excessive alcohol consumption $>20$ $\mathrm{g} /$ day), those with hepatitis B virus (determined by the presence of hepatitis B surface antigen), those with hepatitis $\mathrm{C}$ virus (determined by the presence of hepatitis $\mathrm{C}$ antibody), or those with some other history of liver disease (Wilson's disease, hemochromatosis, autoimmune hepatitis, and primary biliary cirrhosis). We also excluded subjects who had taken medications known to have a potential to provoke fatty liver in the past year. Subjects with chronic medical diseases, such as malignancy were also beexcluded.

All patients were subjected to the following:

1. Assessment of history and physical examination to obtain clinical data used for the diagnosis of CAD and NAFLD.

2. ECG (Electric cardiography).

3. Laboratory Investigations:- Blood samples were collected from patients and submitted to the following: Serum bilirubin, aspartate aminotransferase (AST), alanine aminotransferase (ALT) ,Lipid profile, Fasting Blood Glucose, Hepatitis B surface antigen and an antibody to hepatitis $\mathrm{C}$ virus.

4. Diagnosis of NAFLD was made based on the ultrasound findings. All ultrasound examinations were performed by one radiologist using the same device (Philips HDI 5000, Bothell, WA). andcriteria.The presence of a fatty liver was identified by characteristic echo patterns such as a diffuse increase in the echogenicity of the liver compared with that of the kidney Echogenicity of liver was compared to the echogenicity of the left kidney.

5. Assessment of steatosis and fibrosis was performed using the transient elastography technique (FibroScan).It was performed by FibroScan 502, touch (Echosens, Paris, France) machine. The device estimates liver stiffness in kilopascal $(\mathrm{kPa})$ and liver steatosis in decibel per meter $(\mathrm{dB} / \mathrm{m})$. Measurements were performed on the right lobe of the liver through intercostal spaces on patients lying in the dorsal decubitus 
position with the right arm in maximal abduction. The tip of the probe transducer was covered with coupling gel and placed on the skin, between the rib bones.

6. Diagnostic coronary angiography to detect the severity of CAD .Coronary Artery Disease was greded and measured according to Gensiniscore.Gensini score was calculated by taking into consideration regional importance and degree of coronary artery stenosis (10). Lumen diameter by $25 \%, 50 \%, 75 \%, 90 \%, 99 \%$ and $100 \%$ percent stenosis was given the narrowing score, respectively $1,2,4,8,16$ and 32 . According to the importance of the functional significance of myocardial coefficient identify areas were given significant coefficient of stenosis in the vessel area. This coefficient was $\mathrm{x} 5$ for the left main coronary artery, for proximal left anterior descending artery it was $\mathrm{x} 2.5$, for the proximal circumflex artery it was $\mathrm{x} 2.5$, anterior descending artery to the middle segment it was $\mathrm{x} 1.5$, the right coronary artery, anterior descending artery distal to the first diagonal branch, posterolateral branch marginal branches and for it was $\mathrm{x} 1$, and for the other side branches it was $\mathrm{x} 0.5$. For all the vessels stenosis, strictures separate functional significance scores and the numbers multiplied and the results was collected to create Gensini score.

\section{Ethical Aspects:}

All subjects involved in the current study were informed about the nature and details of the current work and a written consent was obtained for each participant. The study was approved by the Ethics Committee, Faculty of Medicine, south valley University.

\section{Statistical analysis}

Data were analyzed using a Statistical Program for Social Science (SPSS) version 18.0. Quantitative data were expressed as Median IQR . Qualitative data were expressed as frequency and percentage . Chi-square test: was used when comparing non-parametric data. Mann-Whitney U test: was used when comparing between two means (for abnormal distributed data). A one-way analysis of variance (ANOVA), when comparing more than two means.P-values were considered statistically significant at $\mathrm{P}<0.005$.

\section{Results:}

The mean age of studied patients was $47.9 \pm$ 8.4 years, $70 \%$ were males ,there were 52 smokers $(52 \%)$ in the studied patients while all the studied patients were non-alcoholic. As regard comorbidities, there were 70 diabetic patients $(70 \%), 64$ hypertensive patients $(64 \%)$.

Regarding laboratory profile, the median of ALT , AST, Random plasma glucose (FPG), total cholesterol, high-density lipoprotein cholesterol (HDL-C), triglycerides (TG) , S.bilirubin, were $30 \mathrm{U} / \mathrm{L}, 24 \mathrm{U} / \mathrm{L}, 110 \mathrm{mg} / \mathrm{dl}$, $204.5 \mathrm{mg} / \mathrm{dl}, 38.5 \mathrm{mg} / \mathrm{dl}, 179 \mathrm{mg} / \mathrm{dl}$ and $0.57 \mathrm{mg} / \mathrm{dl}$ respectively. All studied patients (100\%) were negative for HCV Ab and HBs Ag (Table 1).

According to ultrasonographic findings, there were 58 patients $(58 \%)$ normal and 42 patients $(42 \%)$ with fatty liver(Table 2$)$.

As regard degree of steatosis, there were 12 patients $(12 \%)$ of S0, 38 patients $(38 \%)$ of S1, 22 patients (22\%) of S2 and 28 patients (28\%) of S3(Table 2).

According to degree of CAD, The mean of Genseni score was 50.9 (Table 2). 
Table 3. shows Highly statistical significant (p-value $<\mathbf{0 . 0 0 1})$ Positive correlation $(\mathbf{r}=\mathbf{0 . 6 5})$

Between Genseni score and degree of steatosis, the mean of Gensini score was $10.5,21.757 .6$ and 102.6 in Grade S0, $\mathrm{S} 1, \mathrm{~S} 2$ and $\mathrm{S} 3$ respectively.

Table 1. Baseline demographic data of all studied patients

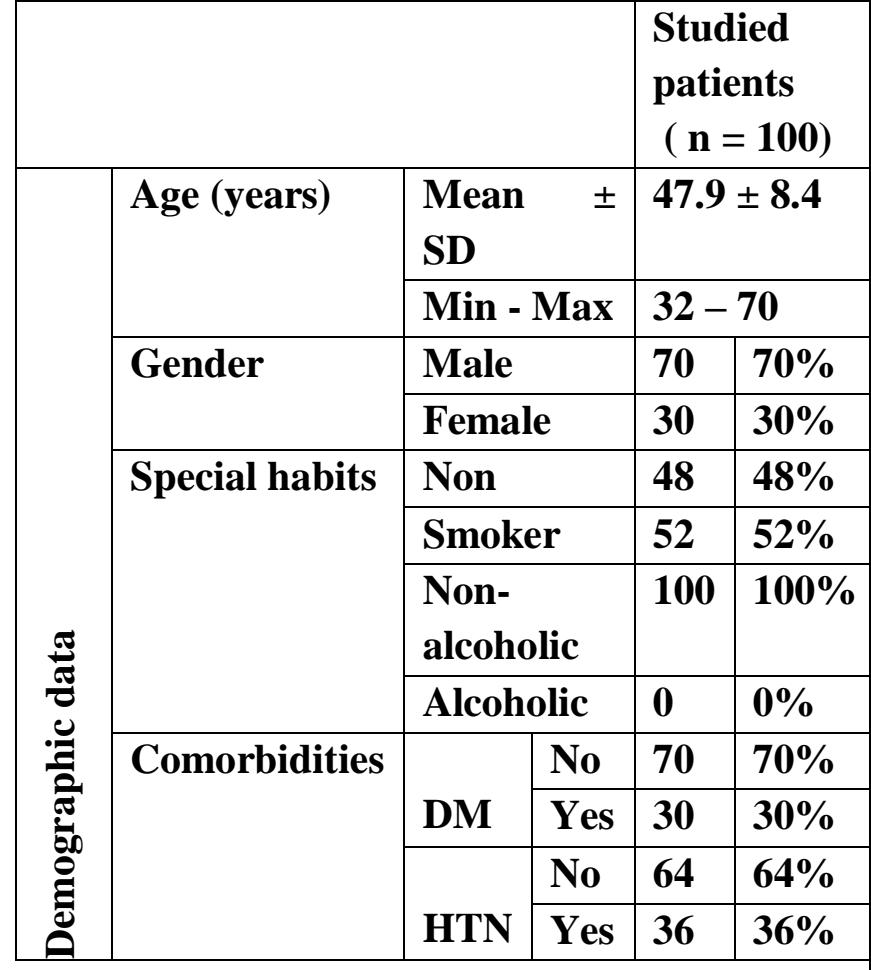

As regard age, the mean age was $47.9 \pm$ 8.4 years with minimum age of 32 years and maximum age of 70 years. As regard gender, there were 70 males $(70 \%)$ and 30 females $(30 \%)$ in the studied patients. As regard special habits, there were 52 smokers $(52 \%)$ in the studied patients while all the studied patients were non-alcoholic. As regard comorbidities, there were 70diabetic patients (70\%), 64 hypertensive patients $(64 \%)$ in the studied patients.
Table2. Baseline laboratory data of all studied patients

\begin{tabular}{|c|c|c|c|}
\hline & CHOL (mg/dl) & $\begin{array}{l}\text { Median - } \\
\text { IQR }\end{array}$ & $(204.5-75)$ \\
\hline & & Min - Max & $(114-383)$ \\
\hline & T.G (mg/dl) & $\begin{array}{l}\text { Median - } \\
\text { IQR }\end{array}$ & $(179-155)$ \\
\hline & & Min - Max & $(50-483)$ \\
\hline & HDL (mg/dl) & $\begin{array}{l}\text { Median - } \\
\text { IQR }\end{array}$ & $(38.5-6)$ \\
\hline & & Min - Max & $(27-67.3)$ \\
\hline & ALT (U/L) & $\begin{array}{l}\text { Median - } \\
\text { IQR }\end{array}$ & $(30-36)$ \\
\hline & & Min - Max & $(9-107)$ \\
\hline & $\operatorname{AST}(\mathrm{U} / \mathrm{L})$ & $\begin{array}{l}\text { Median - } \\
\text { IQR }\end{array}$ & $(18-24)$ \\
\hline & & Min - Max & $(10.5-107)$ \\
\hline$\Xi$ & T. Bil (mg/dl) & $\begin{array}{l}\text { Median - } \\
\text { IQR }\end{array}$ & $(0.57-0.44)$ \\
\hline 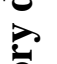 & & Min - Max & $(0.3-1.2)$ \\
\hline ํㅠㄹ & RBS (mg/dl) & $\begin{array}{l}\text { Median - } \\
\text { IQR }\end{array}$ & $(110-50)$ \\
\hline & & Min - Max & $(90-285)$ \\
\hline
\end{tabular}

As regard CHOL, the median CHOL was $204.5 \mathrm{mg} / \mathrm{dl}$, IQR was $75 \mathrm{mg} / \mathrm{dl}$ with minimum $\mathrm{CHOL}$ of $114 \mathrm{mg} / \mathrm{dl}$ and maximum CHOL of $383 \mathrm{mg} / \mathrm{dl}$. As regard T.G, the median TG was $179 \mathrm{mg} / \mathrm{dl}$, IQR was $155 \mathrm{mg} / \mathrm{dl}$ with minimum T.G of 50 $\mathrm{mg} / \mathrm{dl}$ and maximum T.G of $383 \mathrm{mg} / \mathrm{dl}$. As regard HDL, the median HDL was 38.5 $\mathrm{mg} / \mathrm{dl}$, IQR was $6 \mathrm{mg} / \mathrm{dl}$ with minimum HDL of $27 \mathrm{mg} / \mathrm{dl}$ and maximum HDL of $67.3 \mathrm{mg} / \mathrm{dl}$. As regard ALT, the median 
ALT was $30 \mathrm{U} / \mathrm{L}$, IQR was $36 \mathrm{U} / \mathrm{L}$ with minimum ALT of $9 \mathrm{U} / \mathrm{L}$ and maximum ALT of $107 \mathrm{U} / \mathrm{L}$. As regard AST, the median AST was $24 \mathrm{U} / \mathrm{L}, \mathrm{IQR}$ was $18 \mathrm{U} / \mathrm{L}$ with minimum ALT of $10.5 \mathrm{U} / \mathrm{L}$ and maximum ALT of $107 \mathrm{U} / \mathrm{L}$. As regard T. Bil, the median total bilirubin was 0.57 $\mathrm{mg} / \mathrm{dl}$, IQR was $0.44 \mathrm{mg} / \mathrm{dl}$ with minimum T. Bil of $0.3 \mathrm{mg} / \mathrm{dl}$ and maximum $\mathrm{T}$. Bil of $1.2 \mathrm{mg} / \mathrm{dl}$. As regard RBS, the median RBS was $110 \mathrm{mg} / \mathrm{dl}$, IQR was $50 \mathrm{mg} / \mathrm{dl}$ with minimum RBS of $90 \mathrm{mg} / \mathrm{dl}$ and maximum RBS of $285 \mathrm{mg} / \mathrm{dl}$.

Table 3. Description of sonagraphic findings in all studied patients.

\begin{tabular}{|l|l|l|l|}
\hline \multicolumn{2}{|c|}{} & \multicolumn{2}{|l|}{$\begin{array}{l}\text { Studied patients } \\
(\mathbf{n = 1 0 0})\end{array}$} \\
\hline Abd U/S & Normal & 58 & $58 \%$ \\
\cline { 2 - 4 } & Fatty liver & 42 & $42 \%$ \\
\hline
\end{tabular}

This table shows sonar findings in all studied patients. There were 58 patients $(58 \%)$ normal and 42 patients (42\%) fatty liver.
Table 4. Description of fibroscan resaults in all studied patients.

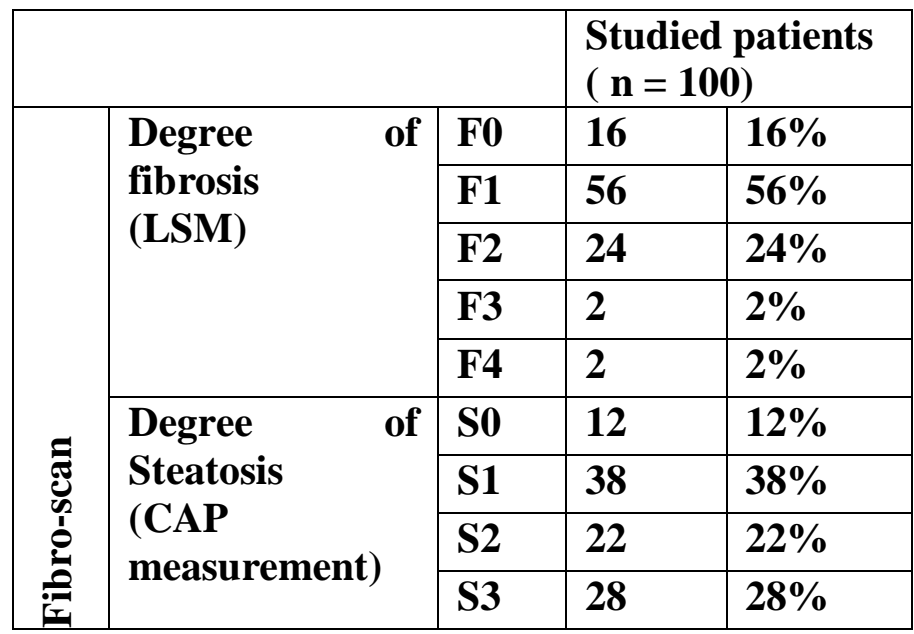

As regard degree of fibrosis, there were 16 patients $(16 \%)$ of $\mathrm{F} 0,58$ patients $(56 \%)$ of $\mathrm{F} 1$, 24 patients $(24 \%)$ of $\mathrm{F} 2,2$ patients $(2 \%)$ of $\mathrm{F} 3$ and 2 patients $(2 \%)$ of $\mathrm{F} 4$. As regard degree of steatosis, there were 12 patients $(12 \%)$ of S0, 38 patients $(38 \%)$ of S1, 22 patients $(22 \%)$ of S2 and 28 patients (28\%) of S3.

Table 5. Description of Genseni score in all studied patients.

\begin{tabular}{|l|l|l|}
\hline \multicolumn{2}{|l|}{} & $\begin{array}{l}\text { Studied patients ( } \\
\mathbf{n = 1 0 0 )}\end{array}$ \\
\hline Genseni score & $\begin{array}{l}\text { Median - } \\
\text { IQR }\end{array}$ & $\mathbf{3 2}$ \\
\cline { 2 - 3 } & Min - Max & $\mathbf{2}-156$ \\
\hline
\end{tabular}

This table shows the description of Genseni score in studied patients. The Median Genseni score was 32, IQR $=70$ with minimum score of 2 and maximum score of 156. 
Table 6. Correlation study between degree of steatosis and Genseni score in studied patients.

\begin{tabular}{|c|c|c|c|c|c|c|}
\hline & \multicolumn{4}{|c|}{ Degree of Steatosis } & \multirow[b]{2}{*}{$\begin{array}{l}\text { p- } \\
\text { value }\end{array}$} \\
\hline & & $\begin{array}{l}\text { So } \\
(\mathrm{n}= \\
6)\end{array}$ & $\begin{array}{l}\text { S1 } \\
(\mathrm{n}= \\
19)\end{array}=$ & $\begin{array}{l}\text { S2 } \\
(\mathrm{n}= \\
11)\end{array}=$ & $\begin{array}{l}\text { S3 } \\
(\mathrm{n}= \\
14)\end{array}=$ & \\
\hline \multirow{2}{*}{ 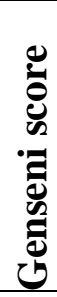 } & $\begin{array}{l}\text { Mean } \\
\pm \text { SD }\end{array}$ & $\begin{array}{l}(10.5 \\
\pm \\
8.09)\end{array}$ & $\begin{array}{l}(21.7 \\
\pm \\
14.7)\end{array}$ & $\begin{array}{l}(57.6 \\
\pm \\
25.3)\end{array}$ & $\begin{array}{l}(102.6 \\
\pm \\
35.3)\end{array}$ & \multirow[t]{2}{*}{$\begin{array}{l}< \\
0.001 \\
\text { HS }\end{array}$} \\
\hline & $\begin{array}{l}\text { Media } \\
\text { n }\end{array}$ & 8 & 24 & 56 & 93.5 & \\
\hline
\end{tabular}

$\mathrm{X}^{2}$ : Chi-square. $\quad$ HS: p-value $<0.001$ is considered non-significant.

This table shows highly statistical significant correlation (p-value $<\mathbf{0 . 0 0 1})$ between degree of steatosis and Genseni score in studied patients.

Table 7.Correlation study between degree of fibrosis and Genseni score in studied patients.

\begin{tabular}{|c|c|c|c|c|c|}
\hline & \multicolumn{2}{|c|}{ Fibrosis } & \multirow[t]{2}{*}{ MW } & \multirow[t]{2}{*}{ p-value } \\
\hline & & $\begin{array}{l}\text { Early } \\
(\mathrm{n}= \\
36)\end{array}$ & $\begin{array}{l}\begin{array}{l}\text { Signific } \\
\text { ant } \\
(n \\
14)\end{array}=\end{array}$ & & \\
\hline \multirow[b]{2}{*}{ 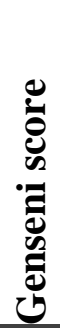 } & $\begin{array}{l}\text { Mean } \\
\mathbf{\pm S D}\end{array}$ & $\begin{array}{l}34.1 \pm \\
33.02\end{array}$ & $\begin{array}{l}94.1 \pm \\
35.5\end{array}$ & \multirow[t]{2}{*}{47.5} & \multirow[t]{2}{*}{$\begin{array}{l}<0.001 \\
\mathrm{HS}\end{array}$} \\
\hline & $\begin{array}{l}\text { Medi } \\
\text { an }\end{array}$ & 24 & 93.5 & & \\
\hline
\end{tabular}

MW: Mann-Whitney Test.

HS: p-value $<0.001$ is considered nonsignificant.
This table shows highly statistical significant correlation (p-value $<\mathbf{0 . 0 0 1})$ between patients with early fibrosis and patients with significant fibrosis as regard Genseni score.

\section{Discussion}

NAFLD is a common disorder which can progress to more aggressive forms of nonalcoholic steatohepatitis (NASH), which can progress to cirrhosis, end-stage liver disease, and eventually hepatocellular carcinoma. Because NAFLD is related to metabolic syndrome and obesity, many patients with NAFLD have coronary artery disease (CAD). Several studies have reported that NAFLD is a risk factor for Coronary Artery Disease.

The results of current study were supported by(Choi et al., 2013)in which 134 adult patients who underwent elective coronary angiography were recruited. Among the 46 patients with CAD, 37 (80.4\%) had evidence of a fatty liver. Coronary artery stenosis was strongly associated with fatty liver in a grade-dependent manner $(P=0.025)$. In binary logistic regression, NAFLD was a significant independent predictor of CAD. In agreement with our study, (Topuz et al., 2014) demonstrated a statistically significant relationship with the severity of NAFLD and CAD. This study included 105 patients who were hospitalized for coronary angiography because of chest pain. Gensini score was used for the severity of coronary artery disease. A total of 71 was detected of NAFLD, 36 patients diagnosed as mild fatty liver (Grade 1), 34 patients diagnosed as 
moderate fatty liver (Grade 2) and one patient with severe NAFLD (Grade 3). Mean Gensini score was $47.6 \pm 29.2$ In those with NAFLD and in those without NAFLD, the mean Gensini was $22.7 \pm 21.6$ ( $\mathrm{p}<0.001$ ). Increase in the degree of steatosis was significantly parallel with the incresing values of the Gensini scores. Gensini score was $37.9 \pm 23.5$ in patients with Grade 1, in patients with Grade 2, it was found $57.5 \pm 31.4$. In a single patient with grade 3 steatosis, Gensini score was found 114 ( $p$ <0.001). The mean Gensini score of 34 patients who had no NAFLD was found $22.7 \pm 21.6$.

In a retrospective cross-sectional study(Kim et al,. 2015 ) , 919 postmenopausal women were enrolled. All of whom underwent cardiac CT. Diagnosis of fatty liver disease was based on an abdominal ultrasonography scan. Women were stratified into three groups by the presence and severity of fatty liver disease. The prevalence of CAC and the mean CAC score significantly increased with the severity of fatty liver disease.

Our findings demonstrate that NAFLD is strongly associated with coronary artery stenosis. The results of current study were supported by(Efe\&Aygün, 2013)in which a total of 372 individuals with or without cardiac symptoms that had undergone MSCT angiography were included in the study. This study demonstrated that the frequency of coronary artery disease in patients with NAFDL was significantly higher than that of patients without NAFDL. In agreement with our study, (Assy et al., 2010)demonstrated that $67 \%$ and $52 \%$ of patients with NAFLD had calcified and noncalcified coronary plaque respectively which was significantly higher than controls and supports high prevalence of NAFLD in CAD patients and vice versa.

(Brea et al., 2005)found an association between NAFLD and carotid atherosclerosis. (Targher et al., 2006) suggested relation between NAFLD and carotid artery wall thickness in type 2 diabetes mellitus patients controlled with diet. (Wong et al., 2011)evaluated the interaction between fatty liver and cardiovascular outcomes using coronary angiograms in a prospective cohort study and demonstrated that fatty liver is associated with CAD independently of other metabolic factors, which is consistent with our results.

\section{Conclusion:}

The present study indicated a statistically significant correlation between $\mathrm{CAD}$ and NAFLD.Conflict of Interest

The authors have no conflict of interest related to this publication.

\section{References:}

Álvarez-ÁlvarezM， Zanetti D, Carreras-Torres R, Moral $P$ and Athanasiadis G, (2017). A survey of sub-Saharan gene flow into the Mediterranean at risk loci for coronary artery disease. European Journal of Human Genetics; 25: 472-476.

Assy N, Djibre A, Farah R, Grosovski M, Marmor A, (2010). Presence of coronary plaques in patients with nonalcoholic fatty liver disease.Radiology ; 254(2): 393-400. 
Brea A, Mosquera D, Martin E, Arizti A, Cordero JL and Ros E, (2005). Nonalcoholic fatty liver disease is associated with carotid atherosclerosis: a case-control study. ArteriosclerThrombVascBiol ;25(5):1045-50.

Chalasani N, Younossi Z, Lavine J. E, et al., (2012). The diagnosis and management of non-alcoholic fatty liver disease: Practice Guideline by the American Association for the Study of Liver Diseases, American College of Gastroenterology, and the American Gastroenterological Association. Hepatology;55:2005-2023.

Choi D. H, Lee S. J, Kang C. D, Park M. O, Choi D. W, Kim T. S et al., (2013). Nonalcoholic fatty liver disease is associated with coronary artery disease in Koreans. World J Gastroenterol ; (38) 6453-6457.

Efe D and Aygün F, (2013). Assessment of the Relationship between Non-Alcoholic Fatty Liver Disease and CAD using MSCT .Arq Bras Cardiol.; 102(1):10-18.

Ibrahim M. M, Ibrahim A, Shaheen K and Nour M.A, (2013).Lipid profile in Egyptian patients with coronary artery disease. The Egyptian Heart Journal; 65(2): 79-85.

Naghavi M, Wang H, Lozano R, Davis A, Liang $X$, Zhou $M$ andAbd-Allah $F$, (2015). Global, regional, and national age-sex specific all-cause and cause-specific mortality for 240 causes of death, 1990 2013: A systematic analysis for the Global Burden of Disease Study 2013. Lancet; 385(9963) 117-171.
Kim D, Choi S. Y, Park E. H, Lee W, Kang J. H, Kim W, et al., (2012). Nonalcoholic fatty liver disease is associated with coronary artery calcification.Hepatology ; 56(2): 60513.

Targher G, Bertolini L, Padovani R, Poli F, Scala L, Zenari L, et al., (2006). Nonalcoholic fatty liver disease is associated with carotid artery wall thickness in diet-controlled type 2 diabetic patients. J Endocrinollnvest ;29(1):55-60.

Wong V.W, Wong G. L, Yip G. W, Lo A. O, Limquiaco J, Chu WC et al., (2011). Coronary artery disease and cardiovascular outcomes in patients with non-alcoholic fatty liver disease.Gut ; 60: 1721-1727. 